Nonlin. Processes Geophys., 18, 529-536, 2011

www.nonlin-processes-geophys.net/18/529/2011/

doi:10.5194/npg-18-529-2011

(C) Author(s) 2011. CC Attribution 3.0 License.

\title{
Nucleation and growth of geological faults
}

\author{
D. Stoyan ${ }^{1}$ and R. Gloaguen ${ }^{2}$ \\ ${ }^{1}$ Institute for Stochastics, Bergakademie Freiberg, 09599 Freiberg, Germany \\ ${ }^{2}$ Remote Sensing Group, Bergakademie Freiberg, 09599 Freiberg, Germany
}

Received: 12 May 2011 - Revised: 28 July 2011 - Accepted: 2 August 2011 - Published: 18 August 2011

\begin{abstract}
We present a new model of fault nucleation and growth based on the Weibull theory, already widely used in fracture research engineering. We propose that, according to a birth-and-growth process, germs (nuclei) are born at random instants at random spatial locations and then grow with time. This leads to a satisfactory formulation of fault length distribution, different from classical statistical laws. Especially, this formulation reconciles previous analyses of fault datasets displaying power-law and/or exponential behaviors. The Weibull parameters can be statistically estimated in a simple way. We show that the model can be successfully fitted to natural data in Kenya and Ethiopia. In contrast to existing descriptive models developed for geological fault systems, such as fractal approaches, the Weibull theory allows to characterize the strength of the material, i.e. its resistance to deformation. Since this model is very general, we expect that it can be applied in many situations, and for simulations of geological fracture processes. The model is independent of deformation intensity and type and therefore allows a better constraint of the seismic risk in threatened regions.
\end{abstract}

\section{Introduction}

Distributions of fault dimensions, such as displacement and length, have been used for decades to understand the evolution of fault systems (e.g., Watterson, 1986; Marrett and Allmendinger, 1991; Cowie and Scholz, 1992). Their relations have implications for rupture mechanics and dynamics, and they provide links to empirical earthquake scaling relations (e.g., Cowie and Scholz, 1992). Various statistical distributions such as gamma (Cardon, 1999), log-normal (Davy, 1993; Castaing et al., 1995), exponential (e.g., Villemin and

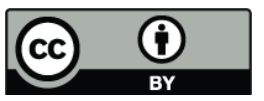

Correspondence to: R. Gloaguen (gloaguen@geo.tu-freiberg.de)
Sunwoo, 1987), or power-law (e.g., Velde et al, 1990; Velde and Dubois, 1991) have been fitted to fault populations.

The power-law is of specific interest since the exponent can be interpreted as a fractal dimension, and tools of fractal theory can be used to quantitatively describe the datasets. Until now, the statistical distributions have only a descriptive value and do not allow inferences about mechanical properties of the deformed medium. None of the statistical laws describes fault distributions at all scales (e.g., Gloaguen et al., 2007).

In this paper we propose to use the Weibull theory to describe fault nucleation and growth. It is based on a stochastic model, which has successful applications in fracture theory of engineers. It leads to a simple distribution function for the lengths of faults. A model parameter $m$, called Weibull modulus, controls this distribution. Its values are known for many engineering materials, and the present paper now yields values for geological materials. The Weibull approach allows a direct quantification of rock resistance to stress (e.g., Lochmann et al., 2007). Until now, and as far as we know, this approach has only been used for 1-D problems in Earth Sciences (Lochmann et al., 2007). We now generalize this formalism to 2-D datasets of faults. Algorithms based on the automatic classification procedure given in Marpu et al. (2006) are used to process remote sensing data.

\section{Geological setting}

The Magadi trough, located in southern Kenya, is considered as the termination of the Kenya rift before it cuts the northTanzanian Craton (e.g. Baker, 1958) (Fig. 1, right). The southern Kenya Rift cuts through a gneissic basement mainly covered by post-Miocene lavas (Gloaguen, 2000). The Ethiopian rift system lies on the Ethiopian-Yemen plateau that likely developed above a mantle plume (e.g., Schilling et al., 1992; Ebinger and Sleep, 1998; Keranen et al., 2004)

Published by Copernicus Publications on behalf of the European Geosciences Union and the American Geophysical Union. 


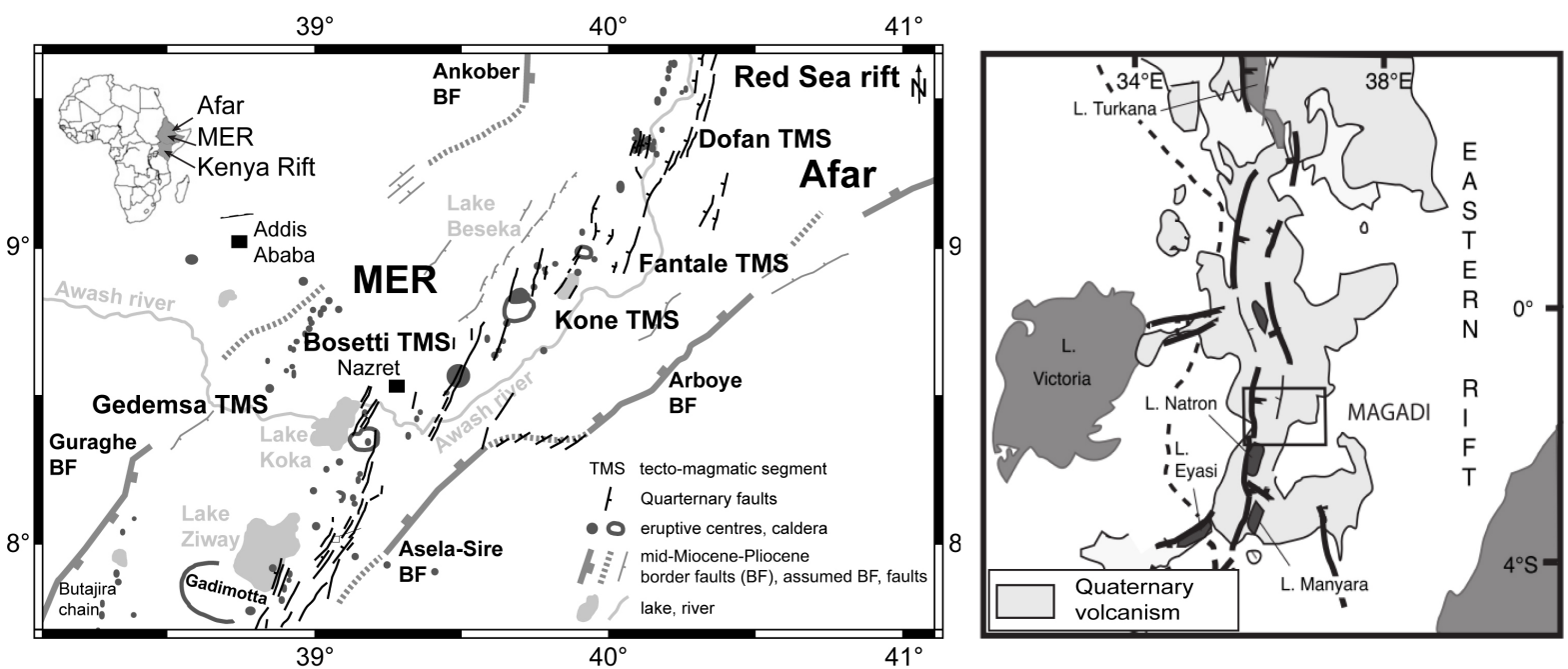

Fig. 1. Localization of the geological area. Left: the Main Ethiopian Rift. Right: the Magadi trough.

(Fig. 1, left). 40Ar/39Ar data show that flood basalts were erupted across a $1000 \mathrm{~km}$ diameter region at $31 \mathrm{Ma}$ (e.g., Hofmann et al., 1997; Pik et al., 2003), prior to or coeval with the initiation of NE-SW extension in the Red Sea and Gulf of Aden (e.g., Wolfenden et al., 2004; d'Acremont et al., 2005). The Main Ethiopian Rift (MER) connects to the North to the Gulf of Aden and the Red Sea via the Afar triple junction. To the south it connects to the Kenya Rift through a complicated set of basins. Recent geodetic measurements indicate a $108^{\circ}$ opening direction between Nubia and Somalia. Quaternary tectono-magmatic segments are superposed on older Red Sea and Aden rift structures within the Afar depression (Kurz et al., 2007; Casey et al., 2006). The crust thickness decreases from $35 \mathrm{~km}$ in Kenya to $20-25 \mathrm{~km}$ in Afar (Tiberi et al., 2005).

\section{Data}

We use orthorectified and speckle filtered Radarsat Fine Beam data (Kenya) as well as SPOT and Landsat data (Ethiopia). Field controls showed that the resolution of the Synthetic Aperture Radar (SAR) and the optical data is sufficient to measure a large amount of the faults that breach the surface. The radar data are acquired in ascending and descending orbits, allowing for a precise measurement of faults otherwise in shadow on images acquired by optical sensors. By virtue of the geometry of side-looking imaging radar, the same scene imaged in opposite directions can be used to effectively map the faults (Henderson and Lewis, 1998). Most of the faults within the Kenya Rift are oriented N-S and are consequently almost orthogonal to the radar beam. Within such a context, it is obvious that SAR images significantly enhance the mapping of the fault systems compared to optical data. The pre-processing step involves a reduction of the speckle in the SAR data using a Gamma filter (Lopes et al., 1993).

As the faults are characterized by steep slopes, a Digital Elevation Model (DEM) can also be used for identification. A DEM can be generated by numerous techniques, the most commonly being based on the stereoscopic potential of optical and radar stereo-pairs. Radar data are one of the sources for generating DEMs and hence are the basic input in the process of fault mapping. The pre-processing step here involves generating new image layers from the DEM with the slope and aspect information. The orientation of the pixels in their corresponding neighborhood gives the direction of the slopes. The gradient of the DEM and the direction information are the input for the extraction algorithm. We used DEMs derived from ASTER data with a spatial resolution of $15 \mathrm{~m}$.

\section{Extraction of faults}

The procedure for automatic object-based classification described in Marpu et al. (2006) and used in Gloaguen et al. (2007) is used to extract the faults. The automatic classification procedure starts with segmenting the image (dividing the image in to smaller homogenous regions). Based on the identified features which characterize the classes, an approximate normal distribution is generated using a minimum-distance clustering. Besides determining which features best separate the object classes from each other, it is essential to know which decision threshold allows maximum separability. The approximate distributions are then corrected using the thresholds of separation for every feature to get the final distribution. The thresholds are determined by Bayes' rule (Nussbaum et al., 2005). Individual fault geometries are resolved accurately. We use manual extraction to validate the datasets. 


\section{Faults}

At the field scale, a fault may be composed of segments that are formed by sub-segments, and usually, direct observation is limited to infra-metric fault planes. The resolution cell of the different types of remotely sensed data will therefore affect the ranking of objects. Thus, depending on the size of pixels there may be confusion between fault and fault zone or fault and segment. The homogeneity of the spatial resolution of the different sensors used in the present study minimizes potential misclassification and guarantees a homogeneous data set. We did not observe measurable differences between the statistics obtained from SAR and optical data.

\section{Fault statistics}

The scaling relationships of fault and fractures have already been used in previous studies for (i) estimation of the relative number of faults whose sizes are smaller than the resolution of the detection method, (ii) determination of the conditions for aggregation of populations of faults, (iii) understanding the evolution of faults in time and space, and (iv) deducing the physical parameters governing the process of fault propagation (e.g. Cowie and Scholz, 1992; Walsh et al., 2002, 2003). Statistical analyses have been successfully applied in low-strain regions where power-law scaling fits the data well (e.g., Scholz et al., 1991) and in higher strain areas where exponential laws seem to describe the fault distribution (e.g., Cowie et al, 1993).

The fit of statistical laws to empirical fault distributions is difficult. This difficulty can be illustrated by the number of laws used to describe fault process in the literature:

- power (e.g. Velde et al, 1990; Velde and Dubois, 1991);

- exponential (e.g. Villemin and Sunwoo, 1987);

- log-normal (e.g. Davy, 1993; Castaing et al., 1995);

- gamma (Cardon, 1999; Bonnet et al., 2001).

There is no consensus on the distribution laws of the various parameters characterizing faults. Some authors have suggested that an exponential law of the form

$N_{p}=\alpha e^{-\lambda p}$

characterizes populations of faults (a) in the early stages of their evolution, when the nucleation of new faults exceeds the growth of existing faults (Cowie et al., 1995), but also (b) after the most important faults reached the boundary of the brittle layer thickness (Ackermann and Schlische, 1997; Bonnet et al., 2001). $N_{p}$ is the number of elements for which the measured parameter is larger than or equal to a given value of $p$ and $\alpha$ is a constant and $\lambda$ is a scaling parameter. Between these extremes (a) and (b) it is assumed that a power law type
$N_{p}=\beta p^{-v}$

describes the distribution (Gupta and Scholz, 2000). $v$ is the exponent of the power law and $\beta$ a constant. A distribution that describes a power law implies a growth factor and a self-similar scaling (Main, 1996; Yielding et al., 1996), the exponent of the power law represents the fractal dimension. This dimension is large when the relative population of small faults is important. Sornette and Davy (1991); Cowie et al. (1995); Cladouhos et al. (1996) have suggested that the exponent $v$ decreases during the evolution of fracturing and thus localisation of deformation onto faults of large size.

None of these statistical distributions allows a complete representation of the fault distributions nor are they based on mechanical properties of the system under stress. The fractal dimension gives a measure of the complexity of the system. Nonetheless, these models rely only on descriptive statistics and do not relate to intrinsic physical properties of the deformed medium. Despite the large number of available tools and robustness the fractal formalism it leads then to non-uniqueness of the interpretation (Shahzad and Gloaguen, 2011a,b).

\section{Fault model}

The complexity of fault systems arises from the interaction and connection of elements during fault growth, and thus the formation of interconnected networks. Based on a fractal analysis Gloaguen et al. (2007) proposed that the fault network can be modeled as an Iterated Function System (IFS) (Barnsley, 1988). The processus starts with small nucleii whose locations are distributed according to a Poisson law. Faulting starts with the asynchronous appearance of segments respecting a given spacing, related to the zone of influence of each fault. In order to compensate stress, faults grow longitudinally. In this process the growing segments connect and form complex fault systems, which are fractal (e.g., Gloaguen et al., 2007; Shahzad et al., 2010). This behavior is attested by observations on very high resolution imagery. The flexures of the foot-wall create depocenters, much smaller than the fault length would suggest. The growth of the depocenter, linked to the vertical displacement, is therefore late with respect to longitudinal growth. The horizontal displacement is controlled by longitudinal growth. As the segments grow longitudinally and perpendicular to the minimum compression stress vector (depending on the heterogeneity of the hosting rock), they enter the zone of influence of other segments and faults. The growth of each segment is random and the increments tend to create longer alignments (in order to allow larger vertical offset). The maximum horizontal displacement along one segment being related to its length, the generation of long linear faults is preferred. It implies that, despite a complex mechanism of formation, fault lengths are good descriptors of the state of deformation in a given region. 


\section{Nucleation model}

Following Jeulin (1994), we propose the ensuing model, which describes only nucleation and length growth and is not in contradiction to the preceding section. We consider a region $B$ of the Earth's surface of arbitrary shape and size. In $B$ fault germ points (short: germs) are distributed randomly. (Their spatial distribution does not matter for our length modelling.) Each germ has some strength (resistance against load), i.e. if the strength is $\sigma$ and the load in $B$ is $\geq \sigma$, the germ is activated and fault growth starts. The random number of germs in $B$ with a strength $\leq \sigma$ follows a Poisson distribution of mean $\Lambda(\sigma)$ with

$\Lambda(\sigma)=\int_{0}^{\sigma} \lambda(s) \mathrm{d} s \quad$ for $\sigma \geq 0$.

For the strength rate $\lambda(\sigma)$ various forms are possible, but we consider here the special case

$\lambda(\sigma)=c \sigma^{m-1} \quad$ for $\sigma \geq 0 \quad$ and $m \geq 1$.

Here $c$ is a constant, which depends on shape and size of $B$ and on the spatial distribution of the germs within $B ; m$ is another parameter, called the Weibull modulus.

Note that for $\sigma \rightarrow \infty \Lambda(\sigma) \rightarrow \infty$, i.e. the total number of all germs in $B$ is infinite. However, of relevance are only the germs of a strength smaller that a given $\sigma$, which is of course finite.

\section{Weibull distribution}

We explain briefly, why the term Weibull theory is used. The theory in Sect. 8 is the fundamental of what some authors call the Weibull theory. The name "Weibull theory" is used since it leads to the Weibull distribution as in (Weibull). The Weibull distribution function has the form

$F(\sigma)=1-\exp \left(-\left(\frac{\sigma}{\sigma_{0}}\right)^{m}\right) \quad$ for $\sigma \geq 0$,

where $\sigma_{0}$ is a scale parameter and $m$ the Weibull modulus, see for example (Evans et al., 1993; Mann et al., 1974; Munz and Fett, 2001).

We estimate the Weibull modulus by fitting the fault lengths histograms by the function derived from the Weibull theory using a maximum likelihood approach. The Weibull distribution appears when we ask for the random load $S$ under which the first germ in $B$ is activated. (In many applications of the Weibull theory one then says that $B$ "fails".) The distribution function of $S, F(\sigma)$, is given by

$F(\sigma)=P(S \leq \sigma)$,

for the nucleation model above

$$
1-F(\sigma)=P(S>\sigma)=P
$$

Table 1. Typical values of the Weibull modulus $m$.

\begin{tabular}{ll}
\hline$m$ & Materials \\
\hline $1.8-2.3$ & oceanic crust; Lochmann et al. (2007) \\
$2-3$ & glass \\
$2-5$ & refractories, piemontite, tourmaline \\
3 & compacted cement paste \\
$3-6$ & human dentin \\
5 & silica gels \\
$5-10$ & technical ceramics \\
$6-12$ & SiC \\
$6-25$ & advanced ceramics \\
$8-16$ & Si3 N4 \\
12 & graphite \\
$>30$ & metals \\
38 & cast iron \\
\hline
\end{tabular}

$=\exp (-\Lambda(\sigma))$.

The last term is the Poisson probability that the random number of activated germs at load $\sigma$ in $B$ is zero. Thus we obtain

$F(\sigma)=1-\exp (-\Lambda(\sigma))$

which is equivalent to Eq. (5) with $\sigma_{0}^{m}=\frac{m}{c}$.

The Weibull distribution and theory have found many applications in reliability and fracture theory, see (Bažant and Planas, 1998; Krajcinovic, 1996; Munz and Fett, 2001). Many fracture nucleation processes follow the model above in good approximation with a power law distribution for $\lambda(\sigma)$ as in Eq. (4). A successful application in tectonics, linking the distance between oceanic fracture zones with their lengths at a given lithosphere strength was presented by Lochmann et al. (2007).

The dimensionless Weibull modulus $m$ characterizes the strength of the material. Values of $m$ for different materials are given in Table 1, resulting from many experiments of engineers, see (e.g. Munz and Fett, 2001). The following shows that the Weibull theory also leads to a distribution function of fault lengths, which is not a Weibull distribution function.

\section{Fault growth dynamics}

We assume that load increases with time, which implies that the number of activated germs increases according to Eq. (4). Each activated germ becomes a fault, the length of which is growing with time. For simplicity of calculation and explanation we assume that the load increases linearly and that the average speed $v$ of growth is constant, so that fault length increases linearly with time $t$. (We would obtain the same results if assuming that load and fault growth are coupled in a suitable manner.) Therefore we speak now instead of load $\sigma$ of time $t$.

("no germ activated at load $\sigma$ ") 


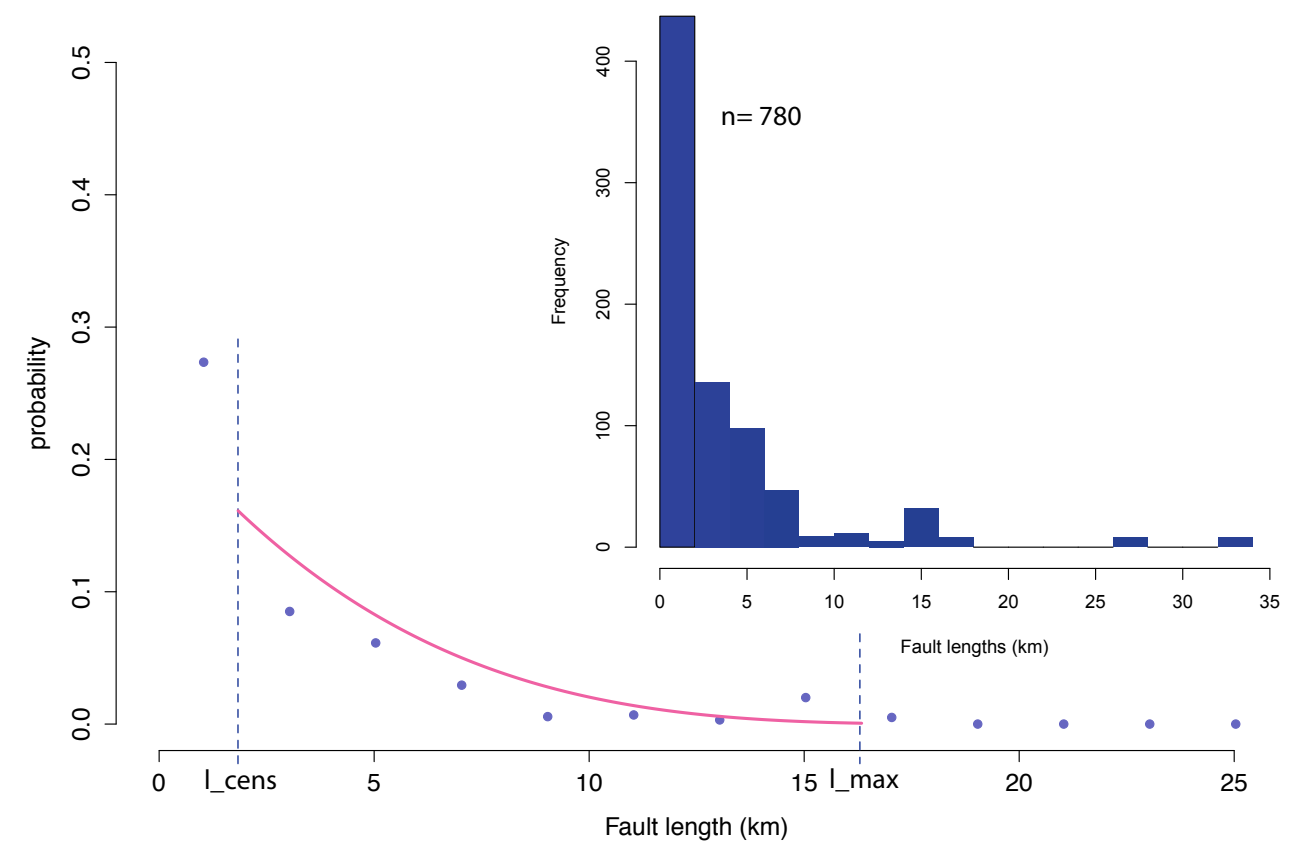

Fig. 2. Statistics for the fault lengths and estimation of the Weibull modulus for the Magadi Faults. The histogram is inserted to highlight the measured number of faults.

In our approach, early (or weak) germs become long faults. New faults, which are more numerous than old faults, are shorter.

We assume here that there is no interaction of faults.

Now we explain how to derive the fault-length probability density function $f(l)$ of the faults existing at time $t$, when the load process started at time 0 . Only faults initiated before $t$ count and clearly earlier faults are longer than later ones.

Under our model, the probability density function $g(u)$ of the instants of activation is

$g(u)=\frac{\lambda(u)}{\int_{0}^{t} \lambda(x) \mathrm{d} x} \quad$ for $0 \leq u \leq t$.

The length of a fault initiated at time $u$ is $l=(t-u) v$ and thus the probability density function of fault length is

$f(l)=\frac{1}{v} g\left(t-\frac{l}{v}\right)$.

With Eq. (4) this yields

$f(l)=\frac{1}{v} \frac{m\left(t-\frac{l}{v}\right)^{m-1}}{t^{m}}$ for $0 \leq l \leq t v$.

If we introduce the maximum fault length $l_{\max }=v t$. Equation (12) becomes

$f(l)=m \frac{\left(l_{\max }-l\right)^{m-1}}{l_{\max }^{m}} \quad$ for $0 \leq l \leq l_{\max }$.

It is $f(0)=\frac{m}{l_{\max }}$ and $f\left(l_{\max }\right)=0$ and between 0 and $l_{\max } f(l)$ is decreasing. An example showing the histogram of fault lengths and the corresponding fitted distribution according to Eq. (13) is shown in Fig. 2.

\section{Statistics}

The aim of statistics for the model above is estimation of the two model parameters $l_{\max }$ and $m$ from fault length data. The estimation of $l_{\max }$ is a delicate task, while for $m$, given $l_{\max }$, a simple maximum likelihood estimator exists. The distribution Eq. (13) should not directly fitted to fault length data. Figure 2 shows a typical situation: the model seems to be suitable for medium values of $l$, while for small and large $l$ there are deviations. Usually, there are some very long faults in a length sample, which should be ignored. Long faults are not statistically representative as they are extremely rare and they may result from pre-existing crustal discontinuities. We recommend to estimate $l_{\max }$ manually in such a way that it makes sense to fit a function as Eq. (13) to the given length histogram.

Furthermore, the observed number of very short faults is often small. This has led some researchers to the assumption that the theoretical length probability density function $f(l)$ satisfies $f(0)=0$, as is the case for log-normal or Gamma. On the other hand, it is sometimes assumed that $f(0)=\infty$, as for the power-law type. An argument which may justify the latter approach is that many very short faults are simply not measured due to sensor resolution or because they are simply not apparent (e.g. buried, covered by vegetation). We assume that there is a limit length $l_{\text {cens }}$ such that faults shorter than $l_{\text {cens }}$ are ignored. The form of the probability density function for lengths longer than $l_{\text {cens }}$ is used to estimate the power-law exponent by extrapolation to small lengths. $l_{\text {cens }}$ 


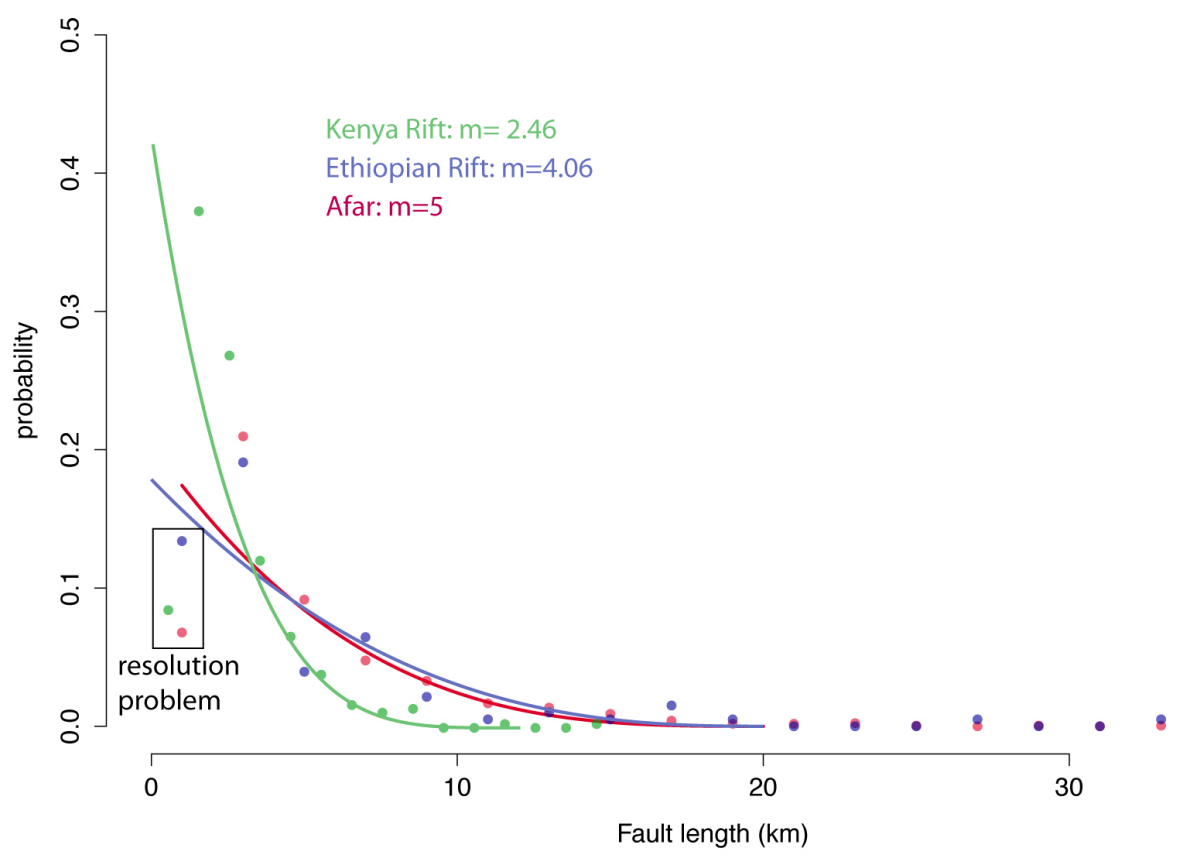

Fig. 3. Estimation of the Weibull moduli for fault systems in the Magadi (green, $m=3.47$ ), the MER (blue, $m=4.06)$ and Afar (red, $m=5$ ).

must be estimated visually. We also assume that there is such censoring, but our model does not lead to $f(0)=\infty$ but to $f(0)=\frac{m}{l_{\max }}$. For estimating $m$ we have a sample of lengths $l_{1}, l_{2}, \ldots, l_{n}$ between $l_{\text {cens }}$ and $l_{\max }$, where $n$ is the number of these lengths. The maximum likelihood estimator is

$\hat{m}=-\frac{n}{\sum_{i=1}^{n} \ln x_{i}}$

with

$x_{i}=\frac{l_{\max }-l_{i}}{l_{\max }-l_{\text {cens }}}$.

By means of Eq. (15) the data are transformed into the interval $[0,1]$, and the probability density is then $f(x)=$ $m x^{m-1}$ The likelihood function is $L\left(x_{1}, \ldots, x_{n}\right)=f\left(x_{1}\right)$. $\ldots \cdot f\left(x_{n}\right)$ and the log-likelihood function $\ln L\left(x_{1}, \ldots, x_{n}\right)=$ $n \ln m+(m-1) \sum_{i=1}^{n} \ln x_{i}$ Equating its first derivative with respect to $m$ to zero yields Eq. (14).

Note that the $x_{i}$ are smaller than 1 and thus the logarithms are negative. Therefore $\hat{m}$ will be positive. The strength of the brittle crust is completely described by the statistical measure of the fault length distribution using the Weibull theory.The modulus is a dimensionless number that is related to the strength of the brittle crust. An increasing Weibull modulus can thus be associated with increasing crustal strength. We consider here the strength as the maximum extensional stress that the crust can withstand without faulting. This assumes a homogeneous strength of the brittle crust, which is approximative in most cases.

\section{Results and discussion}

We applied the model to three fault data sets extracted in the East African Rift System. We selected these areas because they have relatively homogeneous and similar compositions and lithologies. Their brittle crust is predominantly composed by post-Miocene lavas. We thus expect to infer the thermo-mechanical properties of the brittle crust from Weibull moduli estimated using the geometrical properties of the fault system. Those regions are characterized by different crustal thicknesses and thermic gradients. We assess the Weibull modulus as a measure of the distribution of faults in the brittle crust. The empirical Weibull moduli increase from Kenya to Afar, i.e. with decreasing crustal thickness and increasing thermal gradient (Fig. 3). This implies an increasing crustal strength from Kenya north to Afar.

Here, we tentatively explain the increasing strength of the brittle crust with an increasing mechanical decoupling between the brittle and ductile crust from Kenya to Afar as well as a decrease in structural heritage. The structural heritage will affect the crust by creating zones of weakness and therefore reduce the crust's maximum strength. The mode of deformation also differs between Afar and Kenya. In Afar the faults are predominantly generated in mode I (tensile stress) whereas in Kenya the faults are usually expressing mode II (shear stress) behavior. Materials are usually more resistant to mode I than mode II failures. Additionally, a large number of fault are dyke induced in the MER and Afar (e.g. Kurz et al., 2007; Keranen et al., 2004). More data are required to infer the specific causes for this behavior. Nonetheless, 
an increasing material strength is certainly related to higher earthquake magnitudes and this fact seems to reflect the reality in the East African Rift (Keir et al., 2006). Thus, the Weibull model of fault length distributions could be used to assess the seismic risk in threatened regions.

We would like to add two remarks on our model assumptions. The form of the strength rate $\lambda(\sigma)$ as in Eq. (4) is not the only possible. Also other forms are possible, e.g. semilogarithmic or exponential forms. With some mathematical modifications a given fault length probability density $f(l)$ can be transformed in a rate function $\lambda(\sigma)$. The interaction between faults and fault growth is more complicated than we assume. Nonetheless, nucleation processes may still follow our model by a rate $\lambda(\sigma)$, even after the faults start to grow by linkage to form longer faults or cease propagating by entering the stress shadow of older faults. In further work it could be tried to combine our model with numerical models of fault interaction (e.g. Hardacre and Cowie, 2003; Olson, 2004).

\section{Conclusions}

We show that the Weibull theory combined with a natural length growth model leads to a simple fault length distribution function which relates to host rock strength. It fits natural data sets well and combine earlier statistical approaches which have led either to exponential or power-law distributions in one theoretical framework. Our model depends on a parameter, called Weibull modulus, which has the potential to characterize quantitatively the mechanical-theoretical properties of the crust under stress. In this way, the geological fracture behavior can be integrated in the fracturemechanical theories developed by engineers. This model has the advantage to be based on a mechanical-theoretical framework and therefore allows some inferences regarding local crustal deformability. Parts of our model can be used in simulations of geological fracture processes, in particular the nucleation part given by the inhomogeneous Poisson process of germ strengths. If there is a complex interaction between growing faults, the growth-part of the model will be more complicated and other fault length distributions will appear. We are now looking forward to test this model in other tectonic settings.

Acknowledgements. The authors are grateful to L. Ratschbacher for his remark that the nucleation model alone may be still true when other conditions of our model are violated. The authors are very thankful to the Editor, L. Telesca and the reviewers, S. Santini and M. J. Welch for their constructive comments that allowed to greatly improved the manuscript.

Edited by: L. Telesca

Reviewed by: S. Santini and M. J. Welch

\section{References}

Ackermann, R. V. and Schlische, R. W. : Anticlustering of small normal faults around larger faults, Geology, 25(12), 1127-1130, 1997.

Baker, B. H.: Geology of the Magadi area, Geol. Surv. Kenya Rep. 42, 82 pp., 1958.

Barnsley, M.: Fractals everywhere. Academic Press, San Diego, 117 pp., 1988.

Bažant, Z. P. and Planas, J.: Fracture and Size Effect in Concrete and other Quasibrittle Materials, CRC Press, Washington DC, 640 pp., 1998.

Bonnet, E., Bour, O., Odling, N. E., Davy, P. , Main, I., Cowie, P., and Berkowitz, B.: Scaling of fracture systems in geological media, Rev. Geophys., 39(3), 347-383, 2001.

Cardon, H.: Mecanisme de propagation des reseaux de failles: l'exemple du Rift Gregory (Kenya), Unpublished PhD thesis, Univ. Claude Bernard., 1999.

Casey, M., Ebinger, C., Keir, D., Gloaguen, R., and Mohamed, F.: Strain accommodation in transitional rifts: extension by magma intrusion and faulting in Ethiopian rift magmatic segments, Geol. Soc. London Spec. Pub., 259, 143-163, 2006.

Castaing, C., Bourgine, B., Chiles, J. P., Genter, A., Ouilon, G., and Sornette, D.: Multiscale organization of joints and faults revealed by geostatistical, multifractal and wavelet techniques, in: EUG8, Terra Abstracts, Strasbourg, 1995.

Cladouhos, T. T. and Marrett, R. : Are fault growth and linkage models consistent with power-law distribution of fault length?, J. Struct. Geol., 18, 281-293, 1996.

Cowie, P. and Scholz, C. H.: Displacement-length scaling relationship for faults: data synthesis and discussion, J. Struct. Geol., 14(10), 1149-1156, 1992.

Cowie, P., Scholz, C. H., Edwards, M., and Malinverno, A.: Fault strain and seismic coupling on mid-ocean ridges, J. Geophys. Res, 98, 17911-17920, 1993.

Cowie, P. A., Sornette, D., and Vanneste, C.: Multifractal scaling properties of a growing fault population, Geophys. J. Int., 122, 457-469, 1995.

d'Acremont, E., Leroy, S., Beslier, M., Bellahsen, N., Fournier, M., and Robin, C.: Structure and evolution of the eastern Gulf of Aden conjugate margins from seismic reflection data, Geophys J. Int., 160(3), 869-890, 2005.

Davy, P.: On the frequency-length distribution of the San Andreas fault system, J. Geophys. Res., 98(B7), 12141-12151, 1993.

Ebinger, C. J. and Sleep, N. H.: Cenozoic magmatism throughout east Africa resulting from impact of a single plume, Nature (London), 395(6704), 788-791, 1998.

Evans, M., Hastings, N., and Peacock, B.: Statistical Distributions, Wiley, New York, 221 pp., 1993.

Gloaguen, R.: Analyse quantitative de l'extension continentale par imagerie satellitale et optique et radar, Application au rift sudkenyan, Unpublished $\mathrm{PhD}$ thesis, Univ. Bretagne Occidentale., 2000 .

Gloaguen, R., Marpu, P. R., and Niemeyer, I.: Automatic extraction of faults and fractal analysis from remote sensing data, Nonlin. Processes Geophys., 14, 131-138, doi:10.5194/npg-14-1312007, 2007.

Gupta, A. and Scholz, C. H.: Brittle strain regime transition in the Afar depression: Implications for fault growth and seafloor spreading, Geology, 28(12), 1087-1090, 2000. 
Hardacre, K. M. and Cowie, P. A.: Variability in fault size scaling due to rock strength heterogeneity: a finite element investigation, J. Struct. Geol., 25, 1735-1750, 2003.

Henderson, F. M. and Lewis, A. J. : Principles and Applications of imaging Radar, manual of Remote sensing, 3rd Edn., Vol. 2, John Wiley and Sons, 896 pp., 1998.

Hofmann, C., Courtillot, V., Feraud G., Rochette P., Yirgu G., Ketefo E., and Pik R.: Timing of the Ethiopian flood basalt event: implications for plume birth and global change, Nature, 389, 838-841, 1997.

Jeulin, D.: Random structure models for composite media and fracture statistics, in: Advances in Mathematical Modelling of Composite Materials, edited by: Markov, K. Z., World Scientific, Singapore, 239-289, 1994.

Keir, D., Stuart, G. W., Jackson, A., and Ayele, A.: Local Earthquake Magnitude Scale and Seismicity Rate for the Ethiopian Rift, Bull. Seismol. Soc. Am., 96(6), 2221-2230, doi:10.1785/0120060051, 2006.

Keranen, K., Klemperer, S., Gloaguen, R., and EAGLE Working Group: Imaging a proto-ridge axis in the Main Ethiopian rift, Geology, 39, 949-952, 2004.

Krajcinovic, D.: Damage Mechanics, Appl. Math. Mech., Elsevier, Amsterdam, 774 pp., 1996.

Kurz, T., Gloaguen, R., Ebinger, C., Casey, M., and Abebe, B.: Deformation distribution and type in the Main Ethiopian Rift (MER); a remote sensing study, J. Afr. Earth Sci., 48(2-3), 100114,2007

Lochmann, K., Gloaguen, R., and Stoyan, D.: Geometricalstatistical modelling of systems of fracture zones along oceanic ridges, Geophys. J. Int., 170(2), 605-614, 2007.

Lopes, A., Nezry, E., Touzi, R., and Laur, H.: Structure detection and statistical adaptive speckle filtering in SAR images, Int. J. Remote Sens., 14(9), 1735-1758, 1993.

Main, I. G.: Statistical physics, seismogenesis, and seismic hazard, Rev. Geophys., 34, 433-462, 1996.

Mann, N. R., Schafer, R. E., and Singpurwalla, N. D.: Methods for Statistical Analysis of Reliability and Life Data, Wiley, New York, 576 pp., 1974.

Marpu, P. R., Niemeyer, I., and Gloaguen, R.: A procedure for automatic object-based classification, Proceedings of the 1st International Conference on Object-based Image Analysis, 2006.

Marrett, R. and Allmendinger, R. W.: Estimates of strain due to brittle faulting: sampling of fault populations, J. Struct. Geol. 13, 735-738, 1991.

Munz, D., and Fett, T.: Ceramics - Mechanical Properties, Failure Behaviour, Materials Selection, Springer, Berlin, 308 pp., 2001.

Nussbaum, S., Niemeyer, I., and Canty, M. J.: Feature Recognition in the Context of automated Object-Oriented Analysis of Remote Sensing Data monitoring the Iranian Nuclear Sites, Proceedings of Optics/Photonics in Security and Defense, SPIE, 2005.

Olson, P.: Predicting fracture swarms the influence of subcritical crack growth and the crack-tip process zone on joint spacing in rock, Geol. Soc. Special Publication, 231, 73-88, 2004.
Pik, R., Marty B., Carignan J., and Lave J.: Stability of the Upper Nile drainage network (Ethiopia) deduced from (U-Th)/He thermochronometry: Implications for uplift and erosion of the Afar plume dome, Earth Planet. Sci. Lett., 215, 73-88, 2003.

Schilling, J., Kingsley, R. H., Hanan, B. B., and McCully, B. L.: $\mathrm{Nd}-\mathrm{Sr}-\mathrm{Pb}$ isotopic variations along the Gulf of Aden; evidence for afar mantle plume-continental lithosphere interaction, J. Geophys. Res., B, Solid Earth and Planets, 97(7), 10927-10966, 1992.

Scholz, C. H., Dawers, N. H., Yu, Y.-Z., Anders, M. H., and Cowie, P. A. : Fault growth and fault scaling laws: Preliminary results, J. Geophys. Res., 98, 21951-21961, 1991.

Shahzad, F. and Gloaguen, R.: TecDEM: A MATLAB based toolbox for tectonic geomorphology, Part 2: Surface dynamics and basin analysis, Comput. Geosci., 37(2), 261-271, 2011 a.

Shahzad, F. and Gloaguen, R.: TecDEM: A MATLAB based toolbox for tectonic geomorphology, Part 1: Drainage network preprocessing and stream profile analysis, Comput. Geosci., 37(2), 250-260, 2011b.

Shahzad, F., Mahmood, S. A., and Gloaguen, R.: Nonlinear analysis of drainage systems to examine surface deformation: an example from Potwar Plateau (Northern Pakistan), Nonlin. Processes Geophys., 17, 137-147, doi:10.5194/npg-17-137-2010, 2010.

Sornette, D. and Davy, P.: Fault growth model and the universal fault length distribution, Geophys. Res. Lett., 18, 1079-1081, 1991.

Tiberi, C., Ebinger, C., Ballu, V., Stuart, G., and Oluma, B.: Inverse models of gravity data from the Red Sea-Aden-East African rifts triple junction zone, Geophys. J. Int. 163, 775-787, 2005.

Velde, B. and Dubois, J.: Fractal analysis of fracture in rocks: The Cantor's Dust Method. Reply, Tectonophysics, 198, 112-115, 1991.

Velde, B., Dubois, J., Touchard, G., and Badri, A.: Fractal analysis of fracture in rocks: The Cantor's Dust Method, Tectonophysics, 179, 345-352, 1990.

Villemin, T. and Sunwoo, C.: Distribution logarithmique selfsimilaire des rejets et longueurs de failles: exemple du Bassin Houiller Lorrain, C. R. Acad. Sci. Paris Serie II, 305, 1309-1312, 1987.

Walsh, J. J., Nicol, A., and Childs, C.: An alternative model for the growth of faults, J. Struct. Geol., 24, 1669-1675, 2002.

Walsh, J. J., Bailey, W. R., Childs, C., Nicol, A., and Bonson, C. G.: Formation of segmented normal faults: a 3-D perspective, J. Struct. Geol., 25, 1251-1262, 2003.

Watterson, J.: Fault dimensions, displacement and growth, Pageoph, 124, 365-373, 1986.

Weibull, W.: A statistical theory of strength materials, Royal Swedish Institute for Engineering Research, Stockholm, 45 pp., 1939.

Wolfenden, E., Ebinger C., Yirgu G., Deino A., and Ayalew D.: Evolution of the northern Main Ethiopian rift: Birth of a triple junction, Earth Planet. Sci. Letts, 224, 213-228, 2004.

Yielding, G., Needham, T., and Jones, H.: Sampling of fault population using sub-surface data: A review, J. Struct. Geol., 18, 135-146, 1996. 